\title{
Las condiciones laborales en las compañías teatrales de José Podestá (1872-1937)
}

\author{
(1ía Noguera \\ Universidad de Buenos Aires-Universidad Nacional de las Artes, Argentina \\ lianoguera@yahoo.com.ar
}

Fecha de recepción: 19/03/2018. Fecha de aceptación: 18/04/2018.

\begin{abstract}
Resumen
José Podestá es un hito ineludible en la historia del teatro argentino. Con él se inició la poética del actor popular y se consolidó el éxito de los dramas gauchescos y el sainete criollo. Iniciado en la arena del circo como acróbata y luego como payaso, posteriormente formó y dirigió varias compañías teatrales en Uruguay y Argentina. Los análisis sobre las obras teatrales que representó y los estudios sobre su actuación han sido abundantes a lo largo de la historia de los estudios teatrales. Sin embargo, el estudio de las condiciones laborales de los artistas en el período de surgimiento y auge de José Podestá son casi inexistentes. Es por ello que en el presente artículo nos proponemos dar cuenta de las relaciones entre el contexto político de la Argentina durante el período 1872-1937, las condiciones laborales de este país y el modo en el que los artistas del espectáculo las experimentaron, tomando como caso paradigmático las compañías teatrales que José Podestá formó entre fines del siglo XIX y principios del XX.
\end{abstract}

\section{Working Conditions in José Podestá's Theatre Companies (1872 - 1937)}

\section{Palabras clave}

teatro;

artistas;

artistas;
condiciones laborales; compañía teatral; Podestá

\begin{abstract}
José Podestá is an inescapable milestone in the history of Argentine theatre. The poetics of the popular actor began with him and he also consolidated the success of the dramas gauchescos and the sainetes criollos. After initiating his career in the arena of the circus as an acrobat and then as a clown, he formed and directed several theatrical companies in Uruguay and Argentina. The analyses of the theatrical works that he represented and the studies on his style of performance have been abundant throughout the history of theatrical studies. However, the study of the working conditions of the artists in the period of emergence and boom of José Podestá are almost non-existent. It is for this reason that, in this article, we aim to consider the relations between the political context of Argentina during the period 1872-1937, the working
\end{abstract}

Keywords

Theatre; Artists; Working Conditions; Theatre Company; Podestá 
conditions in this country and the way in which performing artists experienced them, taking as a paradigmatic case the theatrical companies that José Podestá formed between the late nineteenth and early twentieth centuries.

\section{Introducción}

Ricardo Falcón (1986) señala que durante los últimos decenios del siglo XIX los trabajadores no recibían indemnización alguna. No había reglamentación para las jornadas laborales y el trabajo de las mujeres y los niños eran una gran preocupación puesto que sus salarios eran inferiores al de los hombres y se les exigía mucho más, por ejemplo a las mujeres se le pedía exhibir una buena conducta. Las fabricas de bolsas, cigarrillos, vidrio, tejido, planchado y mensajería eran las que empleaban mayoritariamente a las mujeres y el sector de la construcción fue el responsable de emplear a los menores de edad. Ellos realizaban las mismas tareas que los adultos, pero su salario era inferior y, en muchos casos, estos niños eran sostén de familia. La situación laboral de las mujeres y los niños fue una de las causas principales del movimiento obrero, que se inicio años después de esa primera huelga, en 1890 . Pero sólo recién en 1907 (año en el que se creó el Departamento Nacional de Trabajo que se encargaba de arbitrar en los conflictos de los trabajadores), y posteriormente a la huelga general de 1902, se sanciona la Ley 5291 que prohíbe la contratación de menores de 10 años. Sin embargo, si se presentaba una autorización por parte de un mayor, ellos podían trabajar.

Estas condiciones laborales no fueron excluyentes del ámbito artístico y en algunos casos encontramos que la situación fue aún más crítica, porque su regulación ha demorado inclusive más tiempo que en otras áreas del trabajo. En relación con los trabajadores del espectáculo, Karina Mauro (2014) señala que las compañías teatrales de fin de siglo se caracterizaron por la precariedad e informalidad de sus condiciones laborales. Las compañías, y en especial las de circo, tenían una estructura familiar en la cual tanto hombres, mujeres y niños trabajaban a la par y el oficio se aprendía mediante la transmisión de saberes de los adultos y la imitación por parte de los restantes integrantes.

En cuanto a las condiciones laborales de los niños en las compañías de circo nos interesa rescatar el caso de Rosita de la Plata. A los 6 años vendía flores en el Circo Arena de Corrientes y Paraná y a los 8, fue contratada por la Compañía Ecuestre de Cotrelly para trabajar en Cenicienta. Según los relatos de Bosch (1969), Cotrelly veía muchas aptitudes en ella y fue por eso que le dio al padre de Rosita 1.000 pesos para llevarla a Europa y allí enseñarle el oficio. El contrato "estipulaba -como era usual en esa época- que debía trabajar sin paga por diez años" (Bosch, 1969: 41). Rosita, con 18 años se convirtió en una artista de renombrada fama internacional y regresó a la Argentina con un contrato de Frank Brown. Conoce luego a los Podestá, trabaja con ellos, se casa con Antonio, pero el matrimonio no dura. Para lograr su independencia, afectiva y laboral, Frank Brown compra su contrato y ella se casa con él. La historia de Rosita, como la de muchos otros niños -pero también adultos- en el circo muestra que las condiciones del trabajo eran muy cercanas a la esclavitud. Esta condición respondía en parte a un deseo de concretar sus sueños de artistas, en parte por necesidades económicas y en parte porque no conocían otra forma de vida. En relación con ello, Beatriz Seibel afirma que los artistas del circo "trabajan por necesidad y porque les disgusta retirarse; se van adecuando a sus posibilidades físicas (y laborales, agregamos nosotros). Dejan la acrobacia con los años para pasar a la comicidad, a adiestrar animales, a trabajar como actores únicamente" (2005: 85).

Son las condiciones laborales de estos artistas de fines del siglo XIX aquellas que nos interesa analizar en el presente artículo, en especial, a partir del estudio de un artista 
del espectáculo que ha marcado los cimientos de nuestro pasado teatral, José Podestá. A fin de alcanzar este objetivo, hemos establecido un estudio por fases de las compañías que este actor y luego actor-empresario ha conformado entre fines del siglo XIX y principios del XX, las cuales hemos denominado: la primera, intuitiva y asistematizada (1872-1884); la segunda, de reconocimiento y consolidación (1884-1901); la tercera, empresarial y epigonal (1901-1937). Estas tres fases evidencian no sólo los cambios que se produjeron en torno a la organización laboral y estética de sus compañías, sino que también se encuentran en estrecha vinculación con los cambios políticos y económicos que se produjeron en la Argentina de fines del siglo XIX y XXI. ${ }^{1}$

\section{Los inicios de un actor nacional}

Los padres de José Podestá fueron inmigrantes genoveses, quienes se asentaron a principios de 1840 en Montevideo y luego, en 1846, se trasladaron a Buenos Aires donde nacieron sus dos primeros hijos: Jerónimo y Luis. En 1851 retornan a Uruguay y allí se completa la familia con el nacimiento de Pedro, José, Juan, Graciana, Amadeo y Pablo. José inició sus primeros contactos con el circo en 1872, momento en que asistía a las funciones que se realizaban en Montevideo. Con un grupo de amigos comenzó a ensayar algunas pruebas que copiaban de las funciones que veían, en el espacio que hoy conocemos como Parque Rodó. Posteriormente, se instalaron en una cantera de la Calle Convención e Islas de Flores y fue allí donde realizaron sus primeras representaciones ante el público. La entrada era a la gorra y lo recaudado se repartía entre los integrantes. Tuvieron bastante éxito y a raíz de ello José Podestá funda la Cooperativa Juventud Unida, cuya finalidad era realizar representaciones en fiestas ya sea de forma paga o a beneficio. Las crónicas y estudios sobre José Podestá coinciden en señalar que su debut oficial fue en el Circo Henault en la ciudad de El Tala, Uruguay. Juan González Urtiaga cuenta cómo fue esta travesía:

\section{Salen en carreta hacia El Tala (Departamento de Canelones). Las fuertes Iluvias les hacía dificultoso en transitar. No existían caminos y el arroyo Tala muy crecido, les impedía pasar hacia la otra orilla. Tuvieron que hacerlo a través de una cuerda extendida y pasar de a uno sobre los hombros de Henault que de esa forma imitaba al famoso equilibrista Blondin cruzando el Niágara (s/f: 9-10).}

Así, y tras esta gran peripecia circense, José Podestá realizó el reemplazo de un trapecista catalán, Enrique Caballé, quien falleció a raíz de una caída en plena función. Por esta representación recibió un pago de 25 pesos (además de casa y comida), lo cual según González Urtiaga constituía una pequeña fortuna para esa época. Hacia 1877, José y sus hermanos, que ya habían formado una compañía, conocen a Pablo Rafetto, quien los contrató para trabajar en su circo y con quien realizaron funciones como bailarines de cuadrilla en el Teatro Solís. Luego, trabajaron durante dos años en el Circo 18 de julio, lugar que ellos mismos alquilaron y en el cual la entrada, en un principio costaba dos reales (posteriormente alcanzó el valor de 1 peso), pero también se colocaba una bandeja en la puerta en la cual el público colaboraba a voluntad. Lo recaudado sirvió para construir su primer circo: el Arena, en las calles montevideanas de Andes y Mini. Con este circo realizaron giras por el país, pero en Canelones sufrieron varias dificultades económicas y debieron regresar a Montevideo. Allí, y ante el fracaso económico, emprendieron su viaje hacia Buenos Aires. Denominaron a la Compañía Rosso-Podestá, se instalaron en el Jardín Florida (Florida y Paraguay) y debutaron a los pocos días. Realizaron once funciones, pero estalló la revolución mitrista y tuvieron que suspender. Luego de un tiempo, y ya calmado el clima políticosocial, el empresario Rafetto los contrató nuevamente y realizaron varias giras por el interior del país. Con respecto a esa época, Antonio Podestá, uno de los hermanos menores de Pepe, recuerda:
1. Para dar cuenta de estas fases fue fundamental el hallazgo que hemos realizado en el Archivo Jacobo de Diego del Instituto de Estudios Teatrales de Buenos Aires (Argentina) de los libros contables de la compañía de José Podestá, el cuaderno de correspondencias establecidas con diferentes artistas de su época y las críticas periodísticas de las obras estrenadas durante diferentes giras, entre otros materiales. Cabe señalar que si bien estos materiales se registraban en el catalogo del Instituto, muchas de las cajas en las que se encontraba estos materiales fueron consultadas por primera vez por nosotros y así también contribuimos a la catalogación de estos en los registros del INET. Además, los documentos y textos que hemos relevado en La Biblioteca Criolla del Instituto Iberoamericano de Berlín (Alemania) durante una estancia de investigación posdoctoral (CONICET, 2015) también se constituyeron en un material pertinente para la reconstrucción y análisis de los aspectos y las condiciones de la gauchesca teatral en particular y de la literatura popular de principios de siglo XX en general. Por último, los archivos de ARGENTORES y AGN nos permitieron analizar la recepción y circulación de las obras teatrales relativas a las compañías de Podestá durante las primeras décadas del siglo XX. 
¡Tiempos bravos aquellos para viajar con el circo! El ferrocarril no llegaba más que al Azul y teníamos que hacer largas distancias en carretas tiradas por bueyes. Entonces no había caminos y se conocían las alambradas. En ocasiones llegábamos a las tolderías de los indios. ¡Ah, supimos bien lo que era la pampa y la vida del gaucho! A veces nos agarraba un temporal en medio campo y allí teníamos que aguantar días y días bajo las lonas en medio de los barrizales. Aprovechábamos esas paradas para ensayar e instruirnos. Los mayores nos enseñaban a los más chicos, no sólo los números de circo sino también aquello que ellos habían aprendido en la escuela, especialmente Pepe que nos leía el Martín Fierro (“Años de escena", Aquí está, VII (753).

Juan González Urtiaga cuenta cómo fue esta travesía:

Salen en carreta hacia El Tala (Departamento de Canelones). Las fuertes Iluvias les hacía dificultoso en transitar. No existían caminos y el arroyo Tala muy crecido, les impedía pasar hacia la otra orilla. Tuvieron que hacerlo a través de una cuerda extendida y pasar de a uno sobre los hombros de Henault que de esa forma imitaba al famoso equilibrista Blondin cruzando el Niágara (s/f: 9-10).

Tras culminar su contrato con Raffeto, regresaron a Buenos Aires y luego se trasladaron nuevamente a Montevideo. Allí los contrató el Circo Chiarini para actuar como pruebistas en La Colonia (Uruguay), donde Pepe tuvo que reemplazar a un payaso que se había enfermado gravemente. Es en ese momento que nació Pepino 88, su famoso personaje que lo llevó a la fama y le posibilitó posteriormente el encuentro con la producción dramática que lo consolidó en el centro del incipiente campo teatral finisecular de la Argentina, a partir de la escenificación de la mayoría de los dramas gauchesco escritos por ese entonces.

Ahora bien, a partir de las descripciones previas podemos señalar que la asistematicidad, la necesidad (artística), pero también la tragicidad, son los rasgos preponderantes de la primera fase. Observamos que los contratos que se establecieron no responden a un plan estético ni económico específico, sino a la demanda por parte de los empresarios de la época en pos de sustituir la falta de recursos humanos que la misma práctica circense sufre (como es el caso de la muerte del equilibrista y la enfermedad grave del payaso, que en ambos casos Pepe Podestá debe reemplazar). En esta demanda por parte de los empresarios reconocidos, Podestá se adaptó de manera intuitiva a la vez que comenzó a conocer cómo se establecen los acuerdos extra artísticos. Con respecto a los salarios, y considerando los relatos de algunos integrantes de esta compañía, no presentan para esta fase una lógica específica, ya que muchas veces los espectáculos eran a la gorra o directamente gratuitos. Tal como lo recuerda Antonio Podestá en relación con los momentos iniciales de su familia en el circo:

Nuestra casa de Montevideo era un gimnasio y en la playa había una cantera con la forma de un anfiteatro donde trabajábamos los domingos y días de fiesta. Era un teatro de la naturaleza, al aire libre. Llegábamos a tener mucho público. No se cobraba la entrada pero la gente para premiarnos nos echaba vintenes ("Años de escena", Aquí está, VII (753), 26 de agosto de1943).

En el caso que hubiese salario, éstos eran quincenales, y tal como lo documenta la viñeta de la fotografía extraída del artículo "La vida en el circo", del Archivo de recortes periodísticos de Jacobo de Diego (1913), se aplicaban multas y descuentos arbitrarios a los artistas. Asimismo, una información importante para esta primera fase es la de conocer cómo estaba integrada la compañía de circo. A partir de un cuaderno de notas del investigador Jacobo de Diego (Archivo, caja 42), quien se preocupó por establecer el árbol genealógico de los Podestá, podemos acceder al modo en el que se organizaba 
la Compañía Carlo, de la cual José Podestá formó parte. Advierte la nota inicial de De Diego que para esta sistematización se basó en los programas de la época que solían aparecer con reproducciones fotográficas pero "no se puede descifrar con precisión cada uno de los rubros que van diseñados con numeración correlativa" (De Diego, cuaderno de Notas, s/f). No obstante, él establece el siguiente orden:

1. Jorge Federico Carlo, Directores y Propietarios

2. Cándido Ferráz, Director de la compañía Sudamericana agregada.

3. Mlle. Amelia Carlo. Gran ecuestre del Circo d'Este de París y célebre en su equilibrio sobre la cuerda y en su admirable solo de tambor.

4. Mlle. Zilda Casali. Ecuestre, equilibrista y domadora de serpientes

5. Sra. Ambilina Ferraz. Gran ecuestre gimnasta.

6. Ermelinda Gonzaga. Acróbata

7. Miss Addie Austin. Gran ecuestre y mima americana.

8. Mlle. Virginia Casali. El relámpago ecuestre y gimnasta.

9. Sra. Camila Pérez. Gran equilibrista

10.Sta. Medea Podestá. Gimnasta y acróbata

11.Anita Casali. Amazona y mima.

12.Jorge y Federico Carlo. Reyes de la alfombra. Acróbatas sin rivales y autores de los admirables violines diabólicos

13.José Paulista Ferráz. Ecuestre equilibrista y gimnasta.

14.Mr. Frank Brown. Ecuestre y acróbata.

15.José Juan Podestá "Pepino el 88". Acróbata y gimnasta.

16.José Coppi. Ecuestre y saltador

17. Luis Casali. Gran ecuestre y malabarista.

18. Alejandro Scotty. Acróbata y gran equilibrista especial en su trabajo en el alambre flojo.

19. Eugenio Prosperi. Gran caballerizo ecuestre.

20.M. Juan Pratesi. Director del cuerpo coreográfico.

21.Juancito Casali. Ecuestre y trapecista.

22.J. José Podestá. Acróbata y trapecista

23. Cuerpo infantil. Harry y Hattye; niños Carlo. Ecuestres, gimnastas y trapecistas.

24. Cuerpo infantil Paulo y Medea, niños Podestá. Acróbatas y gimnastas.

25. Fructuoso Pereira. Ecuestre y saltador.

26.Antonio Podestá. Gimnasta y acróbata.

27.Mr. Mert Clark. Hombre salamandra. Rey del fuego.

28.José Podestá. Gauchito oriental

29. Cachito y Aurora ventura. Trapecista y acróbata.

30. Ermenegilda y Minervino, niños Gonzaga. Contorsionista, acróbatas y saltadores.

31.Tonu y Keny. Hermano Taro. Contorsionistas japoneses

32. Marivel Gómez. Gimnasta.

33. Martín Pereira, niño de goma de 3 años y medio de edad. Gimnasta y contorsionista.

34. Martinian Blodey. Acróbata.

35.L. Nicolisia. Funámbula

36.José Bechún. Saltador.

37. Clowns Frank Brown

38.Clowns José Podestá "Pepino el 88"

39. Robert Scotlaim. Presentador de perros y monos sabios.

40.Pascual Ventura. Gimnasta.

41.José Podestá. Clown, gimnasta y cómico.

42.Juan Podestá. Clown, gimnasta y cómico.

43. Antonio Podestá. Clown, gimnasta y cómico.

44.Alejandro Scotty. Clown, gimnasta y cómico.

45.Juanita Casali. Clown, gimnasta y cómico.

46.El niño Boaldo Payasito. Clown, gimnasta y cómico. 
47. Sesenta caballos en libertad y de trabajo. Catorce perros sabios. Ocho culebras.... Ocho monos; entre ellos el gran cinéfalo ecuestre, que trabaja con tal maestría que ha causado admiración donde hasta ahora fue presentado.

48. Caballos amaestrados a la voz de mambo. Los 5 brincos. Primera, Segunda, Pinto, Lo mismo y Maldito.

49. Caballos en libertad. Fanny, Danny, Orfetal, Bayard, Relámpago. Estrella.

50.El mulo saltador. P.F. Barnum

51. Doce petizos escoceses. Los únicos pequeños caballos hasta ahora conocidos.

52. Pocas funciones. La compañía dará función todas las noches con excepción de los lunes. Los viernes función de moda según la práctica hecha en París, Londres, Madrid y Viena. Los domingos y días festivos: dos funciones, una a las 14: 30 y otra a las 20: 30 .

A partir de esta catalogación, podemos observar la gran cantidad de artistas que implicaba a esta compañía a la vez que evidencia los roles fijos ejercidos. Además, permite, en el caso de José Podestá, verificar su pasaje de roles: de acróbata a payaso y de payaso a gauchito oriental. También evidencia el rol que cumplían los niños diferenciados por familias y establece las diversas nacionalidades de sus artistas. Asimismo, la acotación indicada en el punto 52 por De Diego, junto con el relato de Antonio Podestá previamente señalado, da cuenta de las jornadas laborales de esta compañía que, sumado a los recuerdos de Pepe (2003), muestran extensas jornadas de trabajo. Muchas veces los artistas, y luego de culminadas las funciones, debían ensayar durante las madrugadas y por estas horas de trabajo no percibían pago alguno. A esto se lo conoció como el suplicado. Sin embargo, un aspecto a destacar es que ya en esta primera fase la compañía de Podestá consideraba un día de descanso los días lunes. Otro aspecto a destacar es que el vestuario era confeccionado por ellos mismos o sus familiares con los recursos que contaban. Así lo muestra el primer traje que lució Pepino 88, que tal como lo documenta Urtiaga (s/f) fue confeccionado por la madre de Pepe con sábanas y los parches negros pertenecían a un viejo levitón de su padre.

\section{Hacia la consolidación: 1884- 1901}

El contexto político de la Argentina del 80 está marcado por el inicio de la presidencia de Julio Argentino Roca (1898-1884), cuyo nuevo régimen se impuso con el lema paz y administración con el fin de culminar con los conflictos políticos y económicos de los años anteriores. En su discurso de asunción del 12 de octubre de 1880 proclamó que se había establecido "para siempre (...) el imperium de la nación (...) sobre el imperium de la provincia y que la ley de capitalización de Buenos Aires era el punto de partida de una nueva era" (en Sábato, 2012: 287). Así, su gobierno se caracterizó por la centralización del poder estatal, sobre todo en lo que refiere a política militar, territorial, fiscal ${ }^{2}$ y administrativa. El general Roca fue sucedido por Miguel Juárez Celman, cuyos primeros años de presidencia se caracterizaron por la bonanza económica y la concentración del poder en sus manos y su grupo político. Llegó a ser el líder del PAN (Partido Autonomista Nacional) y el presupuesto nacional pasó de ser de 63 a 148 millones en el período 1886 y 1889. Sin embargo, poco después la situación se revirtió y se generó una aguda recesión. Se incrementó notablemente la deuda externa y se produjo un indiscriminado otorgamiento de concesiones ferroviarias que culminaban en la nulidad de la extensión de los contratos para la ampliación de las redes del ferrocarril que ya en el gobierno de Sarmiento se habían realizado.

En este marco, se produce la segunda fase de las compañías teatrales de José Podestá, que comienza con el estreno de Juan Moreira en el Teatro Politeama de Buenos Aires y culmina con la separación de los hermanos José y Jerónimo Podestá, luego de una representación del drama gauchesco Calandria. Una separación que fue leída por la
2. "La unificación en materia monetaria fue una de las principales adoptadas por el gobierno, y había tenido como objetivos terminar con la pluralidad de monedas y concentrar la emisión en manos del estado nacional. Así se creó con éxito el peso moneda nacional para todo el país, se estableció su convertibilidad y se fijó su valor en oro plata" ( Sábato, 2012: 303) 
crítica como una oposición de intereses estéticos entre los hermanos pero que, según las declaraciones de la hija de Jerónimo, Blanca Podestá, en una nota periodística registrada en el archivo de Jacobo de Diego del Instituto de Estudios Teatrales (INET) de Buenos Aires, pone al descubierto que dicha ruptura respondió, simple y sencillamente, a intereses amorosos. Allí, Blanca cuenta que: "fueron dos muchachas las culpables, dos partiquinas alegres que integraban el conjunto de bailes criollos de los Podestá" (El Día, 31 de agosto de 1960). La esposa de Jerónimo no le dio opción, debía echarlas si quería continuar con su familia. Pero José Podestá de ninguna manera quería que las bailarinas abandonasen la compañía, y por tal motivo, se realizó la separación. Es interesante señalar la división de bienes que establecen los hermanos, la cual evidencia el éxito económico que la compañía tuvo en esta segunda fase y que se caracterizó por los estrenos de la mayoría de las obras teatrales gauchescas. Así lo detalla Blanca Podestá:

Sobre el escenario se colocaron cuanto poseían, era para deslumbrar. Había allí la mar de rastras, de cuchillos, de boleadoras; petrales, estribos, los más hermosos arreos. Fueron separando a un lado y a otro. Lo que uno y otros preferían. El reparto se hizo sin discusión. Había también un armonio que mi padre quería mucho y se lo llevó. Jerónimo y sus hijos se fueron al teatro Libertad; Juan, Antonio, Pablo y Pepe, con los hijos del primero; Totón, Hebe, Marino y Aparicio rumbearon para el Apolo (El Día, 31de agosto de 1960).

Además, en esta segunda fase, Podestá debió enfrentar un juicio con la viuda de Gutiérrez por los derechos de autor de Juan Moreira, el cual pierde. Recordemos que con esta obra en manos de Podestá se habilitó el encuentro y circulación de los bienes culturales propios de los sectores populares y la cultura de elite de finales del siglo XIX. Sabemos que destacados nombres de la highlife porteña, y tal como recuerda Podestá: "invadieron modesto circo y aplaudieron a nuestros modestos gauchos" (2003: 21). De esta manera, y a raíz del éxito de su Juan Moreira, la elite porteña masculina, que gustaba ver teatro culto junto a sus esposas, reconoció el valor de la pieza, pero también el valor de la propia actuación de Podestá proponiendo así una doble visibilización: la del cuerpo del gaucho Moreira y la del cuerpo de Podestá como actor.

Ahora bien, así como Podestá y su compañía comenzaron a tener fama en el incipiente campo teatral y social finisecular, se hizo necesario a la vez sistematizar la organización de sus artistas y enfrentarse con los diversos aspectos de regulación económica y laboral de estos trabajadores. Para poder dar cuenta de cómo comenzó a profesionalizarse esta compañía nos hemos basado en el fondo documental del Archivo de Jacobo de Diego (INET), en el cual hemos hallado numerosos documentos que nos permiten reconstruir las condiciones de trabajo de estos artistas. Un ejemplo de ello es la correspondencia que tanto José Podestá como su secretario Rafael Picasso establecieron con diferentes representantes teatrales y artistas durante los últimos años de esta segunda fase. Estas cartas nos permiten caracterizar varios aspectos que conciernen al ámbito laboral como así también cuestiones específicamente estéticas de esta compañía. Comenzaremos por las cuestiones administrativas.

En la carta que firma Rafael Picasso (Santa Fe, 12 de septiembre de 1891) podemos observar el interés y la organización que la compañía tenía en relación con los fondos destinados para la beneficencia como así también los porcentajes destinados a la compañía. Dice la carta: “1) De la entrada bruta que se haga, se deducirán \$200 de la compañía, incluyendo en estos gastos, teatro, música, imprenta, empleados; 2) Del resto de la entrada bruta una vez deducidos los dichos \$200, el 50\% será para beneficio del Hospital y el 50 \% para el pago de la compañía." Además, y en caso de las temporadas en el interior del país, la compañía la realiza por un mes y con dos funciones diarias (Carta de Picasso, 28 de octubre de 1892). Un aspecto a resaltar es el 
que refiere a los músicos en la compañía puesto que ella se encargaba de la selección de la banda de manera completa y no permitía que los empresarios provinciales o del exterior designaran al maestro de la banda. En carta firmada por José Podestá a los Sres. Crodara y Carbone (10 de enero de 1891), se deja asentado que los músicos cobrarán los siguientes salarios: " 2 pistones a 60 cada uno, un bajo a 60 , un trombón a 60, 1 bombardín y un requinto a 60 cada uno, y el maestro de la banda 120 pesos".

Además, también en esta fase observamos las asociaciones que la compañía realizó con renombrados músicos de la época como es el caso de Gabino Ezeiza. Payador y contrapuntista, nacido en argentina, fue uno de los más importantes músicos a quien se lo honra el día 23 de abril. Algunos especialistas consideran que Ezeiza fue el introductor de la milonga en la payada y la excelencia de su accionar no podía quedar por fuera de la Compañía Podestá-Scotti. Una carta de José Podestá a Gabino Ezeiza (10 de marzo de 1891) nos informa sobre las negociaciones que la compañía estableció a fin de que este músico se incorpore a la representación de los dramas gauchescos. Así también evidencia el lugar de reconocimiento, no sólo artístico, sino también económico que Podestá ofrece al músico:

He hablado con Cordara respecto del asunto y vimos de cantar 405 funciones, bien solo o en contrapunto con Navas o con otro o tomar parte en los dramas criollos, casi en la seguridad que será un suceso. El ordenado que podemos darte sería de pesos 100 por función. Te advierto que estos cien pesos son oro, que en moneda de Buenos Aires es 3800 390, de modo que haya o no buenas entradas tú sacas un provecho que en las actuales circunstancias sería una locura despreciar. Los gastos de viaje hasta aquí serían por cuenta de nosotros.

Otro aspecto a destacar por parte de la compañía es aquella que refiere a las normas de seguridad y los aspectos técnicos que los teatros debían presentar para que ella realice sus funciones, aspecto que sustenta el grado de organización y control minucioso que se experimenta en esta fase. En una carta fechada el 12 de septiembre de1891 y firmada por Picasso, encontramos la preocupación que el secretario de Podestá manifestaba en relación con la seguridad contra incendios y solicitó que este tema esté verificado antes de que los artistas lleguen a la ciudad "así no se demoran en los ensayos y produce contratiempos". Con respecto a las condiciones técnicas de las salas, en carta firmada por Picasso y dirigida al responsable del teatro de Gualeguay leemos: “...tendrá usted la bondad de decirme la capacidad del teatro, qué grandor tiene la sala, cuántos palcos y qué número de personas cabe en cazuela y paraíso. Sobre todo la dimensión exacta de la sala para ver si cabe el picadero" (21 de octubre de 1891). Asimismo, dada la magnitud de la compañía como así también los requerimientos técnicos para las representaciones, esta debía asegurarse en cada gira que sus gastos sean cubiertos. Según la carta de Pissano del 19 de enero de 1893 , la compañía tiene un presupuesto de 7000 pesos mensuales, los cuales deben ser cubiertos en las representaciones:

Nuestro contrato se fijará en $50 \%$ cada una de las partes pero si el $50 \%$ no alcanza a cubrir nuestro presupuesto $U$. nos abonaría lo que faltase hasta cubrir dicha cantidad. Si excediese, sería la ganancia que como empresarios de la compañía tendríamos nosotros. Todos los gastos serán por cuenta de U. como igualmente los pasajes y conducción del material a todos los puntos que vayamos.

Cabe señalar que por estos años se produjo paulatinamente el abandono por parte de Podestá de sus representaciones como Pepino 88 y para su reemplazo, la compañía decidió contratar a Manuel Padín, uno de los principales actores circenses de la Argentina de fines del siglo XIX, quien también fue mago y fotógrafo. Si bien la oferta no fue aceptada, la carta de Picasso (27 de octubre de 1891) no sólo muestra el modo y 
plazo de contratación que se le ofrecía a Padín: un año y que el artista establezca "lo que crea justo ganar", sino también el modo en el cual Podestá le entregaría su legado: "Don Pepe le dará a U. todas sus canciones y le enseñará las payasadas especiales de él e inventadas por él. El, en casos excepcionales y su salud lo permite, hará algunas entradas, como por ejemplo en el beneficio de él u otro caso por el estilo. Mientras tanto, usted será el clown de la compañía."

Ahora bien, en lo que refiere a la organización interna de la compañía, cabe señalar que en esta etapa se continúa con el sistema de categorías por roles, pero se agrega la jerarquización de estos en función de sus salarios. En esta época las compañías se organizaron en torno a un sistema de roles fijos: primer actor dramático, primer actor cómico, galán joven, galán joven cómico, primer característico, segundo característico, actores de conjunto, primera actriz dramática, primera actriz cómica, dama joven, dama joven cómica, primera característica, segunda característica, actrices de conjuntos. Estos roles, afirma Pellettieri, "eran fundamentales a la hora de distribuir las ganancias y para acceder a los papeles de mayor jerarquía había que hacer carrera dentro de la compañía" (2001: 147). Con respecto a esto, en una carta fechada el 10 de enero de 1891, Podestá informa a un representante teatral del interior del país, cómo estaba compuesta su Compañía a fines de arbitrar los medios necesarios para el pago de sus viáticos, indicando nombre y rol que cumplían. Encontramos 49 artistas, caballerizos que cuidaban a los caballos, 10 niños (que pagaban medio pasaje) y 8 músicos. Una compañía prolífera que para el funcionamiento exitoso que tuvo, debió sentar una política verticalista en la cual se privilegió el registro y ordenamiento de cada una de sus actividades artísticas y contables. Sin embargo, y a pesar de la gran organización que alcanzó la compañía Podestá-Scotti, las jornadas laborales continuaban sin reglamentarse y presentaban extensas horas de trabajo. En carta de José Podestá a Juan C. Nosiglia (14 de mayo de 1891), a propósito de su obra Santos Vega o El desgraciado, o sea Vega el Cantor (cuyo estreno se realizó en 1893), leemos:

Respecto a "Vega" aun no he podido hacer nada, trabajamos todas las noches, con las payadas de Gabino, se acaban las funciones a las 12 1/2 01 ; al día siguiente y henos aquí, que aunque la voluntad se nos salga por las puntas de los pelos como se nos sale, no podemos estudiar ni trabajar nada, he aquí porqué su drama duerme, y no en el olvido, sino esperando un tiempo oportuno para ensayarlo.

Una mención especial con respecto a esta fase fueron los problemas relacionados con la representación de los dramas gauchescos, dramas que representan el leitmotiv estético y social de esta compañía en esta segunda fase. Dice Podestá:

Yo ando por estos pueblos del Sud luchando por el puchero y llevando bien alto el estandarte de nuestro joven teatro enseñando gaucherías justamente aquí donde fue la cuna del tipo legendario; para que las nuevas generaciones, degeneradas ya, tomen ejemplos de lo que fue el que, con su esfuerzo, nos dejó la libertad que hoy gozamos" (carta 23 de diciembre de 1897).

Por tal razón, y dado el enorme interés sobre ellos, comenzaron las disputas por la puesta en escena de estas obras. En una carta de Rafael Picasso del 31 de octubre de 1891 a Elías Regules, observamos esas disputas como también la falta de regulación sobre los derechos de autor y, por lo tanto, los plagios que se suscitaban en esta época, en este caso, de Martín Fierro, del autor uruguayo Elías Regules:

Amigazo Regules. Montevideo. Sin ninguna suya a qué contestar la presente tiene por objeto recordarle que en una de sus estimables nos decía que creía que su Martín ya no lo daríamos más por el poco efecto que había hecho en Buenos Aires y en esa le dijimos que poco valdríamos nosotros si no salía adelante el Martinito 
y a fuerza de vueltas y vueltas, vueltas de acá y de allá, Martín gusta hoy más que Moreira... (...) La gran noticia del día: la célebre compañía Ecuestre, gimnástica, acrobática y de Dramas Criollos “Luis Anselmi y Cía.” Está dando su Martín. ¿Quién le ha facilitado el libreto? Nadie. Han copiado de nosotros, nos han visto en Bs. As. Y lo habrán arreglado a su modo, resultando un asesinato como hacen con Moreira y Cuello. Pero el caso es que lo dan y en Córdoba han hecho furor y han ganado plata, según carta.

Como investigadores teatrales del siglo XIX, sabemos que una de las dificultades para la recuperación de los textos dramáticos gauchescos se debe a que el texto representado muchas veces no era publicado, puesto que se escribía para la actuación (lo que se denomina hoy como dramaturgia del director). Los estudios sobre la gauchesca teatral se concentraron en el análisis de éstos e intentaron dar cuenta mediante reconstrucciones basadas en las novelas homónimas y las críticas periodísticas de la época de aquellos textos que no habían podido hallar. Sin embargo, con el hallazgo de manuscritos pertenecientes a la gauchesca teatral que hemos realizado, ${ }^{3}$ con el estudio de los fondos documentales del Archivo De Diego, y a partir del cuaderno de cartas, como así también de los libros contable de José Podestá, se nos abre un panorama más extenso que no sólo confirma la representación de las obras que hemos hallado por parte de esta compañía, sino que también nos proporcionan otros datos que no sólo refieren a los supuestos plagios que entre compañías se realizaban y que antes mencionábamos. Por un lado, nos brindan información sobre los pagos realizados por derecho de autor, es decir la organicidad y legalidad que alcanza a perfeccionare la compañía en su tercera fase. Por otro lado, nos permite reconstruir el universo de dramas que la compañía representó. A modo de ejemplo, encontramos una referencia, en una carta sin fecha (F.133, hoja 25 de la encuadernación de De Diego) a una obra perteneciente a Alfredo Verzi (autor uruguayo nacido en 1874) y titulada Prudencio Tranquera. Dice Podestá: “pronto entrará en ensayo: ya se están copiando las partes, así que, cuando lleguemos a esa, tendrá el gusto de verla en escena por nosotros".

Como último aspecto a señalar de esta segunda fase pero que anticipa los rasgos de consolidación de la tercera es aquella que comprende al aspecto artístico. Por estos años, encontramos que la compañía evidencia un control detallado, una disciplina rigurosa, sobre los componentes escénicos de los dramas, como así también podemos reconstruir aspectos que refieren a la dirección teatral por parte de José Podestá. El primer punto, y en un Aviso del 15 de septiembre de 1892 firmado por los dueños y el secretario de Podestá, leemos:

Se prohíbe terminantemente que los gauchos salgan con cuellos parados y con botines. Todos tienen la obligación de quedar de gauchos hasta las últimas marchas.

En Fierro que se juegue al tejo. Arturo que saque la damajuana. Todos los artistas, peones y empleados firmarán correspondiente contrato antes de salir para Tucumán, pasarán por la secretaría a firmar hoy a las 5 de la tarde.

Todos los que quiera hacerse traje de gauchos de su propiedad se le adelantará el dinero descontándole después por quincena.

En relación con las preocupaciones estéticas textuales y sobre los aspectos concernientes a la puesta en escena que tenía Podestá, una crítica que el actor le realizó a Agustín Fontanella nos proporciona información sobre uno de los principios constructivos que va a caracterizar la última fase de su compañía: el disciplinamiento y el alto conocimiento sobre el gusto de los espectadores, aspectos que lo consolidan como empresario teatral. Dice Podestá:
3. Durante una estancia de investigación posdoctoral (CONICET), realizada en abril-junio de 2015 en el Instituto Iberoamericano de Berlín (Biblioteca Criolla) y a partir de una búsqueda personal en la Biblioteca Nacional de Madrid hallamos cinco manuscritos más, que podrían cuestionar las aseveraciones hasta aquí difundidas respecto de la gauchesca teatral y de las obras que conformaron el ciclo gauchesco de los Podestá. Estos textos en versiones manuscritas y mecanografiadas son: Hormiga negra (1890), de Eugenio Gerardo López, Por la patria o El desorden del Quebracho (1896), de Orosmán Moratorio, Juan Cuello (1890), de Luis Mejías y José Podestá, Las tribulaciones de un criollo (1894), de Víctor Pérez Petit, Santos Vega o El desgraciado, o sea Vega el Cantor (1893), de Juan C. Nosiglia. 
... su atenta del 19 donde me pide le dé mi opinión sobre su drama “Justicia Humana”... me pone en una apuración de la gran siete, pero con toda franqueza... con pelos y señales... los defectos que a mi juicio le encuentro.

... cuando escriba, no olvide que el asunto debe ser humano, real, natural y sobre todo, mucha unidad de tiempo; sus obras pecan de falta de unidad, se conoce palpable que medita poco al construirlas. Los argumentos para nuestros dramas deben ser genuinamente criollos, diferenciarse de las obras extranjeras en el (¿??), no solamente en el modismo del lenguaje; lo que en ellas se trata debe ser único y exclusivamente de lo que pasa en el río de la plata. ... Justicia Humana es bueno, tal vez sea un tanto inverosímil la olvidada del cuchillo, creo sería más natural... la oferta del cuchillo... voy al segundo cuadro.

\section{Pulpería de Campaña. Es de noche}

....qué hace Juancho a los malhechores. Por mucho que podría andar un caballo con... personas encima, nunca haría más de 12015 leguas en una noche. ¿Cómo se explica que habiéndolos tomado presos, no hayan llegado enseguida al pueblo o a la comisaría en cuya sección ocurrió el hecho?

¿Por qué se ha tardado tantos días sin hacerse la luz, enjuiciando a don Pedro, haciéndolo dudar y en fin que las autoridades ignoran la verdad de lo sucedido, cuando en la actualidad en... horas a mas tardar se sabe lo que pasa en cualquier parte del mundo? (...)

En resumen, la obra podría servir volviéndola a retocar con mucha atención y tiempo (Tandil, 23 de diciembre de 1897).

A partir de esta extensa cita observamos una estricta sujeción a las tres unidades aristotélicas, la concepción de verosimilitud que los dramas debían tener a la vez que propone, en continuación con el ideario romántico decimonónico, la revalorización del color local. La crítica de Podestá se sustenta a la vez en las características propias de la poética gauchesca que fue la preponderante en esta segunda fase. Recordemos que la gauchesca teatral se inicia en 1884 con estreno del drama Juan Moreira, en su versión de pantomima y dos años después, se estrena su versión dialogada. Con ese estreno se conforma un microsistema de enorme productividad dentro de un teatro que se constituye a partir de su emergencia y da inicio a la conformación del campo teatral argentino: consolida un poética textual y actoral (la popular), crea un público y permite, por primera vez en nuestra historia, la aparición del teatro como práctica social (Pellettieri, 2002). Cabe señalar que en la poética textual gauchesca 4 se apela a la representación de un cuerpo marginal, perseguido y fuera de la ley (económica, amorosa y/o política) como fue el gaucho a la vez que escenifican el proceso de encauce político y cultural que este mismo cuerpo experimenta a partir del surgimiento del Estado moderno en la Argentina de fines del siglo XIX y principios del siglo XX. Así, a través de la gauchesca teatral se pone en evidencia un conjunto de prácticas políticas y estéticas que sintetizan el modo por el cual se efectúan los procesos de conformación identitarias de la nación argentina al servicio de una ideología conservadora que operó mediante la singularización y domesticación de un cuerpo marginal para volverlo signo identificatorio de lo que se pretende incorporar y eliminar del cuerpo social. El ciclo de estos dramas se cierra con el estreno de Calandria, obra en la cual se produce el disciplinamiento del gaucho a partir del indulto de Calandria. De esta manera, este cuerpo ilegal se legaliza: de ser gaucho matrero pasa a ser criollo trabajador. Así, a nivel textual, "el héroe se vuelve inofensivo y el conflicto social irreconocible" (Mogliani, en Pellettieri, 2002: 177).
4. Las obras que constituyen este ciclo, y que en su gran mayoría fueron representadas por la compañía Podestá, son: Martín Fierro (1889) de Elías Regules, Juan Cuello (1890), de Luis Mejías y José Podestá, Hormiga negra (189o), de Eugenio Gerardo López, El entenao (1892) de Elías Regules, Julián Giménez (1893) de Abdón Arosteguy, Juan Soldao (1893) de Orosmán Moratorio, Santos Vega - El desgraciado, o sea Vega el Cantor (1893), de Juan C. Nosiglia y José Podestá, ¡Cobarde! (1894) y Las tribulaciones de un criollo (1894), de Víctor Pérez Petit y Por la patria o El desorden del Quebracho (1896), ambas de Orosmán Moratorio y Calandria (1896) de Martiniano Leguizamón. 
Por ello, y teniendo presente este ideario gauchesco, la crítica de Podestá pone el acento en el grado de verdad que Justicia humana relega y establece que esa veracidad no solo debe manifestarse a nivel textual, sino también desde los componentes y las acciones que los actores realizan en la escena. Esta crítica también nos permite observar la ajustada y sistemática forma que el propio Podestá postulaba al momento de escenificar los dramas gauchescos, a la vez que da cuenta de las características de su proyecto creador y que era celebrado por la crítica de la época. Así lo evidencian las críticas periodísticas del año 1895 (Archivo De Diego, caja 42) que destacaban la gran labor de la compañía Scotti-Podestá y señalaban el talento de sus actores: "Gerónimo Podestá (en El entenao) es un pecheador perfecto y María en sus amores despertó entusiasmo del público." Con respecto a Fausto y Las tribulaciones de un criollo, estrenadas el 8 de agosto con un público masivo, la crítica vuelve a distinguir a Gerónimo Podestá como "un verdadero artista y está bien en cualquier papel con ese aire varonil, altivo, resuelto y generoso de un criollo". Asimismo, señalan la popularidad de su circo que contaba con 1500 butacas y estaban siempre llenas. Mención especial tiene el estreno de Juan Cuello (23 de agosto de 1895) que retomando la idea de veracidad que Podestá proponía a Fontanella por su obra Justicia Humana, las modificaciones que el actor realiza sobre los hechos reales de este gaucho son celebradas por la crítica puesto que se integran al horizonte de expectativas del público modelo de la Compañía. Así lo señala la crítica del 24 de agosto de 1895 , recopilada en el Cuaderno de Críticas del Archivo Jacobo de Diego (Caja $\mathrm{N}^{\circ} 42$ ):

Se ha dado por primera vez el drama Juan Cuello, arreglado por José Podestá. El autor del arreglo, aunque faltando a la verdad histórica ha causado una agradable sorpresa entre los espectadores. En el momento en el que el oficial al mando del piquete se prepara para dar la voz de fuego contra el acusado atado ya al banquillo se escucha iViva, Venganza! y penetran los vencedores de Caseros que acometen a los colorados y ponen en libertad al valiente paisano. Estruendosos aplausos recibió el autor de esta variación.

En síntesis, tanto este documento como los anteriormente nombrados dan cuenta de una perfectibilidad, legalización, sistematización y profesionalización que la compañía experimenta en esta segunda fase, que no sólo se concentra en los materiales artísticos de sus puestas, sino también en lo que refiere al ordenamiento económico laboral que se consolida en la tercera fase. Si como señalamos anteriormente con Calandria de Martiniano Leguizamón se produce el fin de la segunda fase de la compañía y el cierre del ciclo gauchesco (con Calandria se evidencia la incorporación del gaucho al sistema estatal); observamos que ese mismo recorrido estético está en sintonía con el devenir económico laboral que la compañía experimenta en esta segunda fase: la compañía se legaliza, se abuena. Al igual que los protagonistas de sus dramas, la compañía de Podestá muestra el traspaso de la frontera que divide la arena circense o picadero del teatro a la italiana, 5 el pasaje de la trashumancia al asentamiento definitivo en la ciudad de sus obras que sintetiza el abandono del desierto y su integración a la civilización. En ese pasaje, se produce su ortopedia: su cuerpo incorrecto, desenfrenado que se desplazaba libremente por la arena del circo, se convierte ahora en un cuerpo sujetado al escenario y a la ciudad, normalizado por las leyes civilizatoria tanto artísticas, sociales como laborales.

\section{José Podestá: actor y empresario}

La Argentina de comienzos del siglo XX se caracterizó, por un lado, por la asunción de los gobiernos radicales de Hipólito Yrigoyen (1916-1922 y 1928-1930), presidente que, por primera vez, fue elegido por el voto universal que sancionó la ley electoral de 1912; por otro lado, por los efectos que la Primera Guerra Mundial (1914-1918)
5. Este cambio se produce a partir del estreno de Calandria, el 21 de mayo de 1896 , en el Teatro La Victoria. 
trajo a nuestro país. Además, y como consecuencia de las políticas implementadas en el fin de siglo anterior, la población argentina contaba con un gran número de inmigrantes quienes se adaptaron a las necesidades del mercado de trabajo argentino (Romero, 2001). Con respecto a las consecuencias de la Primera Guerra Mundial es necesario destacar el gran impacto que tuvo en todos los planos de la Argentina del nuevo siglo: se presentaron dificultades en el comercio exterior, la inversión de capitales extranjeros comenzaron a retraerse, se produjo una paulatina inflación y los salarios laborales disminuyeron a la vez que se incrementó la desocupación. Esta situación produjo que las huelgas se multiplicaran y que alcancen su momento más álgido entre los años 1917 y 1919, momento en el cual se produce la Semana Trágica (entre 7 y 14 de enero de 1919). Por estos años, el campo artístico también se vio afectado con dos huelgas: una, entre el 6 y 19 de mayo de 1919, otra, entre mayo y junio de 1921. Luego de estos incesantes conflictos y variadas manifestaciones por parte de los sectores obreros, culminó la primera presidencia de Yrigoyen, a quien lo sucede Marcelo Torcuato de Alvear.

En este contexto se produjo la tercera fase de las compañías de José Podestá, que como mencionamos previamente, comenzó con el traslado de José Podestá al teatro Apolo en 1901, lugar en el que creó en el mes de marzo la compañía Hermanos Podestá. A los dos años, el 23 de marzo de 1903, se presentó en ese mismo teatro el Primer Concurso Dramático Nacional, en donde el director la compañía del Apolo, abrió el acto. Asimismo, se creó la Sociedad de Fomento del Teatro Nacional, el 30 de marzo de 1903, pero su duración fue breve debido a "la falta de constancia, de solidaridad y de actividad que nos caracteriza en toda obra colectiva por mas importante que sea" (Podestá, 2003: 134). Una incorporación importante para la Compañía Hermanos Podestá, que se realizó el 24 de diciembre de 1903, fue la de Angelina Pagano, ex dama joven y discípula de Eleonora Duse. Ella había traído de Italia su propia compañía con la cual trabajó en los teatros Odeón y Victoria pero al poco tiempo tuvo que disolverla y se sumó a las filas de los Podestá. La actriz debutó con la obra Causasy efectos de Ferraris y traducción de León Pagano.

$\mathrm{Al}$ año siguiente, y debido al gran éxito de las representaciones de la Compañía, José Podestá decidió comprar su propio teatro en la capital porteña. Para ello, realizó tramitaciones con el fin de adquirir los terrenos que se ubicaban en frente del Teatro Politeama (Corrientes y Paraná), compra que se realizaría a 90 pesos la vara:

Para financiar esta operación-de notoria importancia, ya que comprendía más de 3000 varas de un terreno que, con el tiempo, había de aumentar, indefectiblemente, su valor -había conseguido yo un préstamo de 450.000 pesos al $5 \%$ de interés y con amortizaciones a voluntad, debiendo dar, por nuestra parte, como garantía un capital en propiedades de 150.000 pesos, e hipotecar, además, el terreno que adquiriríamos y las construcciones a efectuar. (Podestá, 2003: 155)

Sin embargo, la amenaza de Pablo Podestá de abandonar la compañía hizo echar atrás este proyecto, amenaza que se cumplió recién el 4 de octubre de 1906, momento en el que deja la compañía para forma la propia y lo reemplaza Florencio Parraviccini. "Parra", como solía llamarlo José Podestá, debutó el 7 de octubre de 1906, con el sainete El Panete de Ulises Favaro, a sala llena y con un cartel en boletería de "No hay mas localidades".

Otro cambio fundamental para la compañía de los Hermanos Podestá fue la incorporación de las obras de Florencio Sánchez, quien luego de haber estrenado $M$ 'hijo el dotor y Cédulas de San Juan con la compañía de su hermano, Jerónimo Podestá, en 1905, se trasladó a la compañía de José Podestá y su primer gran éxito allí fue Barranca Abajo. La incorporación de Sánchez no solo introdujo cambios en el aspecto estético de la 
compañía, sino también un incremento de sus ganancias. En el libro de cuentas de la compañía de 1914 (Archivo de Diego) hallamos que de lo recaudado por las obras representadas de Florencio Sánchez: Barranca Abajo, En familia y Los muertos, ésta recibió un total de 16.474 pesos oro de los cuales el $10 \%$ fue destinado a la Sociedad de Autores y el $30 \%$ al autor. Además, en el libro contable de 1916, observamos la variedad de dramas que la compañía representó. Una variedad que se sustentó en la alternancia, por un lado, de los dramas gauchescos como Julián Giménez y Cobard; por otro lado, los sainetes y comedias Barranca Abajo, Los disfrazados, Al campo, El Dr. Frauz, Tranquera, Justicia, Qué calor, La flor de trigo, El amigo, El sargento cordobés, etc. Así también se indican en qué teatros fueron representadas: El Nacional, Victoria, Unión Italiana, Olimpo, Circo Anselmi, entre otros. En el balance perteneciente a julio de ese año observamos las deducciones del 10\% para la Sociedad de Autores y los pagos por derechos de autor, dando como resultado un total de 23.627 pesos oro para la compañía. Tal como la ha indicado Mauro, estas deducciones ya se encontraban preestablecidas desde años anteriores:

Por un lado, los autores agrupados en la Sociedad de Autores, ya contaban con la percepción del $10 \%$ de la recaudación desde 1910. Por otra parte, el teatro nacional experimentaba una época de bonanza producida por la disminución del arribo de compañías extranjeras, causada por la Primera Guerra Mundial. Por último, el contexto de amplia combatividad del movimiento obrero a nivel mundial y nacional, aspecto ampliamente estudiado. Estas condiciones promueven la fundación de la Sociedad Argentina de Actores, que se produce el 18 de marzo de 1919, con la firma de 118 miembros (2015: 2).

La Compañía Hermanos Podestá permaneció en el Teatro Apolo desde el 6 de abril de 1901 hasta el 15 de diciembre de 1908. Allí estrenaron 249 obras, dieron 3249 representaciones y 157 beneficios para sociedades y autores, artistas, gentes de teatro, etc. (Podestá: 2003), pero a causa de la no renovación del contrato, tuvieron que abandonar este teatro y comenzaron su peregrinaje teatral. Su recorrido consistió en el teatro De la Comedia, el Nuevo Politeama de Montevideo, el Olimpo de La Plata, el Olimpo de Rosario y el teatro Argentino de Córdoba. Luego de esto, regresaron al Apolo y José Podestá se asoció, primeramente, con José Brieba y, posteriormente, con Luis Vittone. Con este último formó la compañía Podestá-Vittone y debutaron el 26 de febrero de 1910 con la comedia En el Fuego de Ezequiel Soria. Cabe señalar que con esta compañía participaron de los festejos del Centenario de la Revolución de Mayo, que contaron con la presencia de la Infanta Isabel de Borbón, destacados intelectuales y políticos nacionales e internacionales. Aquello que caracterizó a los discursos del Centenario fue una marcada preocupación por la idea de nacionalidad argentina, puesto que en todo momento se intentaba resaltar el origen criollo de la nación ante la masa inmigratoria a quien se pretendía argentinizar y disciplinar. Es evidente que estos objetivos eran cumplidos por la estética teatral que la compañía Podestá-Vittone proponía a partir de la representación de los dramas gauchescos y sainetes. Por tal razón, esta participación les permitió una gran visibilidad y un enorme reconocimiento por parte de la crítica periodística del momento.

En 1911 se asoció nuevamente con Pablo Podestá y formaron la compañía Nacional Pablo Podestá dirigida por su propietario: José Podestá. Sin embargo, al poco tiempo nuevamente Pablo abandonó la compañía y José decidió abandonar el Apolo. En 1915 volvió a asociarse con Pablo Podestá, formaron la Compañía Pablo Podestá y José Podestá asumió la dirección. Estas idas y venidas entre José y Pablo, los problemas de cartel, de las condiciones artísticas de los espectáculos, así también como algunas referencias a las formas de contratación son explicadas y justificadas con cierta melancolía por José Podestá (2003) como un signo que ya anticipaba la enfermedad de su hermano, que se manifestó en 1919. Recordemos que Pablo Podestá comenzó a sufrir signos de 
deterioro mental por los cuales fue hospitalizado y murió a causa de sífilis en 1923. En este sentido, observamos la persistencia de José Podestá no sólo en el plano sentimental a fin de mantener los lazos familiares dentro de su compañía, sino también en el plano profesional puesto que como empresario teatral sabía del beneficio que su asociación con su hermano Pablo traía a su compañía puesto que él a lo largo de estos años se había destacado como uno de las grandes actores de la escena nacional.

Ahora bien, durante la década del 20, la actividad teatral comienza a complejizarse debido a diferentes aspectos que atañen a las condiciones laborales de sus artistas. Como ya hemos señalado en la primera fase, las jornadas de trabajo aún consistían en extensas horas de trabajo y los días de descanso continuaban si implementarse. Los 24 teatros que componían el campo teatral porteño, se desenvolvían de la misma manera en cuanto a la representación de sus funciones:

La primera función de la tarde era conocida como función matinée, mientras que la segunda era conocida vermouth, era a las 18 horas. (...) el teatro porteño se desarrollaba sin descanso durante todos los días de la semana, los días de mayor asistencia de público eran los sábados y domingos (Caudarella, 2016: 39).

Sin embargo, y tal como lo ha señalado Caudarella (2016), el Concejo Deliberante tuvo presente estas anomalías e intentó establecer políticas para su reglamentación. Una propuesta que surgió para implementar días de descanso estaba relacionada con las desinfecciones que debían realizar los teatros. Se propuso realizarlas cuatro veces al mes posibilitando de esta manera los descansos. Pero esto se vivió como un escándalo para los empresarios y dueños de las salas teatrales, puesto que las pérdidas serían a gran escala. Como resultado negativo de esta negociación, se determinó que las desinfecciones se realizarían en horarios de madrugada, cuando los teatros estaban vacíos.

Recién en 1926 se expresaron más denuncias por parte de concejales que pretendían defender las condiciones laborales de los artistas del espectáculo. Ellos realizaron comunicados denunciando las precarias condiciones de seguridad e higiene en que los actores se encontraban, pero estas fueron acalladas y los concejales debieron retractarse. Inclusive Florencio Parraviccini, concejal por el período 1926-1928, no apoyó los reclamos y recibió las más duras críticas por parte de sus colegas y los partidos opositores. El actor y concejal Parraviccini justificaba la realización de los ensayos nocturnos debido a las condiciones económicas en las que se encontraba la actividad teatral. Tampoco evaluaba que los sueldos eran bajos como así lo había denunciado el partido socialista, sino que consideraba que el mínimo del salario de los artistas superaba aquel que percibían los trabajadores de fábricas o talleres (Caudarella, 2016).

De esta manera, los reclamos por parte de los artistas del espectáculo se incrementaron y originaron la primera huelga de actores en Buenos Aires que se produjo el 5 de mayo de 1919. Según señalaba el acta citada por Caudarella (2016) la Sociedad de Actores solicitó un aumento del $1 \%$ de los salarios para las funciones vermouth y del $2 \%$ de las funciones matineé -a excepción de los días domingos- para todos los actores de las compañías de sainetes, zarzuelas y revistas. Para los actores de compañías de dramas y comedias, la Sociedad de Autores reclamaba un aumento del $2 \%$ para las funciones diurnas, a excepción de los días domingos, y para cada función que se realizara entre medio de la matineé y la función de la noche, aun si se realizara un domingo. Asimismo, se exigía un día de descanso, el cual podía ser determinado por parte de los empresarios teatrales. Si bien luego de largas negociaciones y de alcanzar un acuerdo el 14 de mayo de 1919, los problemas continuaron hasta 1921, momento en el cual se desarrolló la segunda huelga por parte de los trabajadores del espectáculo. Seis años más tuvieron que esperar los artistas teatrales para que algunos de sus reclamos fueran legislados, y así: 
Luego de casi un mes de debates, el 4 de octubre de 1927 el Concejo Deliberante llegó, finalmente a un acuerdo. El proyecto sancionado prohibió los ensayos nocturnos, mejorando indirectamente la calidad del trabajo en los teatros, pero también flexibilizó las multas, estableciendo el cierre del teatro por cinco días en caso de una contravención y no su clausura definitiva, como proponía el proyecto original (Caudarella, 2016: 79)

Previamente a este acuerdo, en un artículo con motivo de las bodas de oro de José Podestá con el teatro, el crítico Carlos Velloso nos proporciona las cifras que el campo teatral recaudaba en este año:

La vida escénica de la República está alimentada por sesenta y ocho compañías nacionales que producen más de seis millones de pesos al año y que reditúan un millón y medio de derechos de autores de los cuatrocientos cuarenta actos que se estrenan anualmente, también, ciento ochenta mil pesos de impuestos solo a la Municipalidad de Buenos Aires (La Nación, 25 de abril de 1925).

Esta información da cuenta de los altos ingresos que la actividad teatral producía, pero aun ante este panorama tan favorable, las condiciones laborales de sus hacedores eran precarias. Si bien no hemos hallado documentación que dé cuenta de la posición de José Podestá ante estas problemáticas que el campo teatral presentó por estos años, inferimos que no quedó al margen de ellas a la vez que suponemos una relación disyuntiva frente a los reclamos. Porque si, por un lado, como actor había vivido y continuaba experimentando ciertas anomalías en relación a su propio trabajo; por otro lado, y ya como empresario teatral, debía atender a las demandas económicas que la actividad le exigía, estableciéndose así una dicotomía en la cual era necesario sentar una posición.

Ahora bien, en relación con las condiciones estéticas de las obras que la Compañía presentó por estas últimas décadas, observamos que comenzó a producirse un repliegue en el éxito de sus funciones. Un documento importante para evidenciar esta afirmación nos lo provee el Cuaderno de Críticas (1918-1921) del Archivo Jacobo de Diego. Allí encontramos una recopilación de las diversas críticas que la compañía (ahora denominada José Podestá y Antonio Podestá) recibió durante sus giras por Santa Fe (Rosario), Entre Ríos (Paraná, Gauleguaychú) y Uruguay (Salto) con las obras: La ley oculta, de Martínez Paiva, La chacra de Don Lorenzo y Piedra de Escándalo, de Martín Coronado y Las campanas. Es interesante que este libro recopile tanto las críticas favorables como las desfavorables. Ejemplo de esto último es la perteneciente a El demócrata, que critica negativamente las obras de Martín Coronado interpretadas por la Compañía por no entender el derecho penal del país y por presentar dilaciones innecesarias a nivel argumental. Dice la crítica:

¡Pobre templo del Arte! Cuánto habrá sufrido al sentir clavarse en su corazón, honda y profundamente la incalificable incultura de este pueblo artístico donde como una aberración la erigieron. (...) La compañía Podestá interpretó regularmente las producciones de nuestro viejo autor, don Martín Coronado: Piedra de Escándalo y La chacra de Don Lorenzo (El demócrata, 9 de agosto de 1918).

Además, las críticas señalan la fase epigonal por la cual transitaron algunos de los actores de la compañía pero aún así destacan la importancia en el presente y el pasado teatral de los hermanos Podestá (Diario Nuevo, 19 de agosto de 1918). Esto es así puesto que el campo teatral porteño de la década del 20 comenzó a inclinarse por el teatro de revista. Si bien la primera revista fue estrenada por los Podestá en 1895 con el nombre de Ensalada Criolla, ya el gusto por parte de José hacia esta estética había sido relativamente abandonado. En este sentido, y considerando el auge que la revista 
porteña tenía entre el público porteño, es lógico entender el descenso en la recepción de las obras de la Compañía Podestá en esta tercera fase. Además, la preocupación por la nacionalidad del teatro se ponía nuevamente en el tapete y parte de la crítica teatral descreía que ella podría reivindicarse a partir de los sainetes y las comedias blancas. Así, poco a poco la compañía de Podestá comenzó a perder centralidad en el campo teatral argentino pero su trabajo incesante con la actuación y como empresario continuó hasta poco tiempo antes de su muerte. En los últimos años, José Podestá se radicó en la ciudad de La Plata, donde prosiguió con las representaciones de sus obras en el teatro que había comprado en esta localidad y que hoy lleva su nombre: Teatro Coliseo Podestá.

Como podemos observar, las características principales de esta tercera fase refieren al grado de adaptabilidad y negociación que Podestá debió enfrentar a fin de mantener sus compañías tanto en el plano estético como en el económico. Para ello la figura de Podestá deviene en empresario de compañía y en empresario de sala, es decir, su responsabilidad se duplica y, por ello, debió enfrentarse con las diferentes vicisitudes que se produjeron no sólo en el campo teatral, sino también en los planos político, económico y social. Como empresario de sala, Podestá necesitó incrementar los controles y las regulaciones de su compañía relegando tal vez sus orígenes como actor en aras de alcanzar el sostenimiento de su empresa teatral en el nuevo contexto de la Argentina de principios de siglo XX.

\section{Conclusiones}

José Podestá falleció el 5 de marzo de 1937 en la ciudad de La Plata. Un gran cortejo fúnebre acompañó a los restos del primer actor nacional en la Casa del Teatro y una gran cantidad de discursos fueron ofrecidos en su honor por diferentes representantes de la cultura y la política argentina. Alrededor de tres mil personas asistieron a su entierro en el cementerio de la Chacarita y la Sociedad de Empresarios Teatrales invitó a suspender las actividades a fin de que toda la comunidad artística pudiera despedir al creador de Pepino 88. Así lo hicieron. Los discursos laudatorios hacia Pepe Podestá coincidían en reconocerlo como el padre de la escena nacional y en distinguir la incesante labor que desde fines del siglo XIX había forjado en nuestro campo teatral. Como actor y como empresario supo articular los medios necesarios para que sus producciones alcanzasen no sólo el reconocimiento del público y de la prensa teatral, sino también el de la cultura y la política de la época.

En las tres fases de las compañías que aquí hemos analizado, mostró un marcado signo de interés por desarrollar y fortalecer las estrategias artísticas y organizativas de sus compañías, evidenciando así una clara perfectibilidad que con los años fue alcanzando. Así, de la arena del circo a la sala a la italiana, de alquilar pequeños galpones a ser dueño de un teatro, de acróbata a primer actor nacional y de primer actor a empresario teatral, José Podestá supo responder a las exigencias del campo teatral y dejó una huella fundante en la historia de nuestra disciplina. Las condiciones laborales de sus compañías no se apartaron del clima político y económico que vivió la Argentina entre los años 1872 y 1937 y que, en los que refiere a ciertos reclamos laborales e irregularidades en el orden legislativo de los trabajadores del espectáculo, aún en el siglo XXI continúan existiendo. Por ello, continuar indagando sobre ellos será el trabajo de nuestras próximas investigaciones. 


\section{Q Bibliografía}

》Bosch, M. (1969). Historia de los orígenes del Teatro Nacional Argentino. Buenos Aires: Solar/Hachette.

》Castagnino, R., (1981). Circo, teatro gauchesco y tango. Buenos Aires: INET.

»Castagnino, R. (1953). El circo criollo. Buenos Aires: Lajouane.

»Caudarella, M. F. (2016). La necesidad del espectáculo. Aspectos sociales del teatro porteño (1918-1930). Rosario: Prohistoria Ediciones.

"Chicote, G. (2013). “De gauchos, criollos y folklores: los conceptos detrás de los términos". Anales de Literatura Hispanoamericana, vol. 42. Disponible en $<$ http: //dx.doi.org/10.5209/rev_ALHI.2013.v42.43652>. pp. 19-34.

» Falcón, R. (1986). El mundo del trabajo urbano (1890-1914). Buenos Aires: CEAL.

» González Urtiaga, J. (SF). José Podestá y Pepino 88.

" Heredia, F. y M. Rodríguez (2006). “Agonía y muerte de Juan Moreira”. Teatro XXI, XII (22), 71-75.

» Klein, T. (1996). Teatro Criollo Rioplatense I. Buenos Aires: Ediciones del Jilguero.

»Mauro, K. (2014). “Actores y mundo del trabajo: apuntes para una problemática construcción identitaria", Actas de las VIII Jornadas de Sociología de la Universidad Nacional de La Plata, La Plata: Facultad de Humanidades y Ciencias de la Educación.

»Mauro, K. (2015). "La Sociedad Argentina de Actores después de la huelga de 1919". XVI Jornadas de Investigación del Instituto de Historia del Arte Argentino y Latinoamericano "Luis Ordaz", Buenos Aires: Facultad de Filosofía y Letras, UBA.

»Mauro, K. (2015). “Trabajo asociativo y Actuación: las cooperativas teatrales y la gratuidad crónica del trabajo actoral”. Actas de las XI Jornadas de Sociología de la UBA "Coordenadas contemporáneas de la sociología: tiempos, cuerpos, saberes", Buenos Aires: Facultad de Ciencias Sociales, UBA.

"Mogliani, L. (2014). El Costumbrismo en el teatro argentino (Tesis doctoral). Edición online disponible en el Repositorio Institucional de la Facultad de Filosofía y Letras, UBA.

»Pellettieri, O. (2002). Historia del teatro argentino en Buenos Aires. Volumen II: La emancipación cultural (1884-1930). Buenos Aires: Galerna.

"Pellettieri, O. (2001). De Totó a Sandrini. Del cómico italiano al "actor nacional" argentino. Buenos Aires: Galerna.

»Podestá, A. (1943), “Años de escena”. Aquí está. Buenos Aires, año VII, № 759, 26 de agosto.

»Podestá, J. (2003). Medio siglo de farándula. Memorias de José Podestá. Buenos Aires: Galerna.

»Prieto, A. (2006). El discurso criollista en la formación de la Argentina moderna. Buenos Aires: Siglo XXI.

»Rodríguez, M. (1999). "El inmigrante italiano y la gauchesca" en O. Pellettieri (Edit.). Inmigración italiana y el teatro argentino. Buenos Aires: Galerna, 17-34. 
» Romero, L. A. (2007). Breve historia contemporánea de la Argentina. Buenos Aires: FCE.

"Sábato, H. (2012). Historia de la Argentina (1852-1890). Buenos Aires: Siglo XXI.

»Seibel, B. (2002). Historia del teatro argentino desde los rituales hasta 1930. Buenos Aires: Corregidor.

"Seibel, B. (2005). Historia del circo. Buenos Aires: Ediciones del Sol.

»Terán, O. (2008). Historia de las ideas en la Argentina. Diez lecciones iniciales. 1810-1980. Buenos Aires: Siglo XXI.

» González Urtiaga, J. (S/F). JoséJ. Podestá y “Pepino el 88”. Montevideo: Centro de estudios de teatro rioplatense.

\section{Archivos consultados}

»ARGENTORES, Buenos Aires, Argentina.

»Biblioteca Criolla, Instituto Iberoamericano de Berlín, Alemania.

"Biblioteca Nacional de Madrid, España.

" Archivo "Jacobo de Diego", Instituto Nacional de Estudios de Teatro (INET), Buenos Aires, Argentina. 